\title{
Diseño líquido: los procesos creativos en tiempos de cambio
}

\section{Liquid Design: Creative Processes in Times of Change}

https://doi.org/10.22235/d33.2379

\author{
Ricardo López-León \\ ORCID: 0000-0001-9653-5525
}

Universidad Autónoma de Aguascalientes, México.

\begin{abstract}
RESUMEN
El objetivo de este artículo es vincular la noción de fluidez expresada en la obra de Zygmunt Bauman- con las prácticas del diseño, para observar su evolución y los retos a los que se enfrentan a nivel profesional y pedagógico. Se presentan resultados de una investigación documental de perspectivas distintas sobre el concepto de liquidez en varios ámbitos, que cubren tres principales aspectos: la discusión sobre los atributos conceptuales como signos de que la sociedad se encuentra en una edad líquida; una reflexión del concepto de diseño líquido a través de siete características identificables en la práctica profesional (colaborativo, multidisciplinar, multimetódico, improvisado, infinito, intangible y glocal); y una reflexión sobre el reto para la enseñanza del diseño en tiempos de fluidez. La comunidad académica puede reconocer en las características aquí identificadas cómo la profesión ha cambiado y así diseñar estrategias para preparar mejor a sus estudiantes. Asimismo, los diseñadores las pueden tomar como guía para expandir su práctica profesional y adaptarse mejor y más rápido a una sociedad fluida. Sirva el diseño líquido como escenario a enfrentar $y$, al mismo tiempo, como un conjunto de habilidades por desarrollar.

Palabras clave: diseño líquido; trabajo colaborativo; creatividad; multidisciplina; pedagogía.
\end{abstract}

\begin{abstract}
The aim of this article is to link the notion of fluidity expressed by Zygmunt Bauman - with design practices, in order to observe their evolution and the challenges they face on a professional and pedagogical level. Here are presented the results of a documentary investigation from different perspectives on the concept of fluidity in various fields, covering three main aspects: a discussion on conceptual attributes as signs that society is in a liquid age; a reflection on the concept of liquid design through seven identifiable characteristics in professional practice (collaborative, multidisciplinary, multimethodic, improvised, infinite, intangible and glocal); and a reflection on the challenge for teaching design in times of fluidity. The academic community can recognize in the characteristics identified here how the profession has changed and thus design strategies to better prepare its students. Likewise, designers can take them as a guide to expand their professional practice and adapt better and faster to a fluid society. May liquid design serve as a stage to be faced and, at the same time, as a set of skills to be developed.
\end{abstract}

Keywords: liquid design; collaborative work; creativity; multidiscipline; pedagogy.

Cómo citar: López-León, R. (2020). Diseño líquido: los procesos creativos en tiempos de cambio. Dixit, 33, 74-88. https://doi.org/10.22235/d33.2379

Recepción: 08/06/2020 :: Revisión: 14/09/2020 :: Aceptación: 23/09/2020 


\section{Introducción: de sólidos a líquidos sociales}

Entre los principales aspectos a abordar en este trabajo, se toma lo líquido entendido como una condición en la que las formas sociales, vistas como "instituciones que salvaguardan la continuidad de los hábitos [y] los modelos de comportamiento aceptables" (Bauman, 2013, p. 7) se descomponen de manera que ya no pueden mantener su forma por más tiempo. Stuart Hall ya decía en sus charlas de 1983 que había momentos en los que se daba un giro histórico, "un cambio en la textura y el tiempo de la sociedad” (Hall, Slack y Grossberg, 2016, p. 2). Ante dichos cambios, los modelos, teorías y conceptos que podían explicar los fenómenos sociales ahora resultan inadecuados y por lo tanto tienen que generarse nuevas perspectivas que acerquen al punto en el que se puedan unir la teoría y la práctica (Hall et al., 2016, p.2).

Así, el concepto de líquido permite observar que "las sociedades contemporáneas parecen estar perdiendo su solidez: las organizaciones se están transformando en algo dúctil y las formas de vida en ellas están convirtiéndose en algo fluido, todos los proyectos tienden a ser flexibles y todas las decisiones reversibles" (Manzini, 2017, p.187). Por lo tanto, esta nueva forma de organizarse de cada sociedad, y de manifestarse y construirse a sí misma, demanda también una nueva práctica del diseño que pueda adaptarse a dichas características, un diseño flexible y reversible.

Sin duda, la rapidez y profundidad de estos cambios han sido desestabilizantes para las estructuras sociales, pero al mismo tiempo se han abierto brechas para posibilidades no vistas antes (Manzini, 2017, p.187). Por ello, el diseño líquido se propone aquí como una expansión de la práctica, una posibilidad de crecimiento, de adaptación a los cambios que han transformado todas las esferas sociales, desde el comercio y la industria, hasta el seno más íntimo de la vida cotidiana.

\section{La disolución del pasado}

Los cambios que se esperaban con la llegada de la modernidad implicaban, según Bauman, la disolución de prácticas tradicionales. Por ello, para el autor, hablar de modernidad líquida no significa una contradicción, pues todo lo que se estaba modificando con el pretexto de modernización tenía en gran parte el objetivo de destruir lo anterior, diluirlo. En ese sentido no es extraño que, en las referencias de principios del siglo XX, cualquier actividad que fuera presentada a la sociedad como moderna se hacía con aires de liberación; una revolución que buscaba derrocar prácticas vistas como nocivas y suplantarlas con nuevas menos rígidas, más flexibles.

Esta revolución había iniciado, de acuerdo con Berman (2006, p.2), desde el siglo XVI en su primera fase, pasando por una "ola revolucionaria" en la segunda y alcanzando a todo el mundo en el siglo XX durante su tercera fase. En esta última vino la visión del modernismo ${ }^{1}$ como una "revolución permanente", entendido también como "la tradición de derrocar a la tradición" (Rosenberg citado en Berman, 2006, p.18) o la consolidación de "una cultura adversaria" (Trilling citado en Berman, 2006, p.19). Así, los acontecimientos del siglo XX pueden ser vistos de dos maneras: la primera es que la revolución ideológica en su origen sí presentaba rasgos de fluidez, pero el mismo esfuerzo por legitimar prácticas inéditas a través del desconocimiento de la anteriores provocó la coagulación de esas prácticas, causando así una nueva época de tiempos sólidos, de nuevas formas tradicionales y de la construcción de instituciones igual de rígidas que las anteriores. La segunda es que tal vez la misma revolución que buscaba disolver lo anterior no se ha detenido, y las características de los tiempos actuales son simplemente una continuación de lo iniciado hace más de un siglo, revolución que solo a la distancia puede ser visible.

Esta revolución puede ser observada también desde la óptica del diseño. En su esfuerzo por separarse de las prácticas artísticas y legitimarse como una actividad rigurosa, las disciplinas del diseño fundaron escuelas,

\footnotetext{
1:: Berman (2006) hace una distinción entre modernidad y modernismo, destacando la primera como una "forma de experiencia vital" (p.1) que concierne experimentar el tiempo, el espacio, uno mismo y a los demás; y refiriéndose a la segunda como un cuerpo de pensamiento y actitudes respecto a la modernidad que se hizo más visible en los años 60 a través de distinto ámbitos del arte. Sin embargo, ambos conceptos comparten el aspecto revolucionario que se destaca en este texto.
} 
desarrollaron métodos y procesos creativos, escribieron libros e iniciaron revistas como plataforma para la difusión de su conocimiento, pero, al mismo tiempo, dichas actividades se fueron volviendo más sólidas. Esa búsqueda obedecía en parte a la racionalidad técnica que era la forma de pensar dominante de la época, la que muchos años después Donald Schön (1982) trataría de desacreditar, sobre todo en lo concerniente a las disciplinas del diseño, pues su forma de conocer y de producir conocimiento, de acuerdo con el autor, es distinta a la de la ciencia básica (López-León, 2018a).

La racionalidad técnica puede haber colaborado en que algunas manifestaciones en la historia del diseño, sean ahora tomadas como el punto de partida para la legitimación de la práctica. La misma Bauhaus, una escuela que debido sus ideas revolucionarias se convirtió en un parteaguas o una llave abierta y fluida de nuevas ideas, 100 años después es uno de los pilares más sólidos del diseño, convirtiéndose aún en un referente para el desarrollo de planes de estudio. Además de la icónica escuela se pueden encontrar otras áreas de solidificación, como la búsqueda principios básicos del diseño por autores europeos y de Estados Unidos o el decálogo del buen diseño promovido por el aclamado diseñador Dieter Rams (Vitsoe, 2019). Por ejemplo, el segundo principio del decálogo habla sobre la importancia de que el diseño sea funcional, pero han surgido desde el diseño sillas que no están hechas para sentarse o exprimidores de cítricos meramente ornamentales en los que no se deben exprimir naranjas. Es decir, el intento por descubrir la esencia del diseño promovió la generación de listas de aspectos que son o deberían ser fundamentales, convirtiéndose en las partes más sólidas de la disciplina, pero que en la actualidad empiezan a ser cuestionados o simplemente ignorados, sin que ello comprometa la práctica del diseño.

Si tomamos como pasado sólido del diseño dos campos, sean estos el desarrollo de profesionales del diseño a través de la fundación de instituciones educativas con métodos específicos y la búsqueda de procesos y fundamentos universales del diseño, podemos identificar algunos aspectos como disolución del pasado. Sobre el primero, hoy más que nunca es posible que una persona que quiera formarse para dedicarse, por ejemplo, a la profesión del diseño gráfico, no necesite recurrir a una institución educativa para lograrlo. Puede acceder a videotutoriales en la web, descargar documentos, manuales de identidad de casos conocidos, e incluso contactar a expertos y diseñadores exitosos para tomar algún consejo. Así, puede generar un portafolio y subirlo a la red Behance, por ejemplo, para que su trabajo pueda ser visto en todo el mundo. Esta persona, posiblemente pueda llegar a ser más exitosa que algún chico o chica que sí se haya formado con métodos tradicionales: en los primeros años entrenarse en técnicas de dibujo y los principios fundamentales del diseño, para luego aprender a manejar software y aplicar fundamentos de áreas más específicas como diseño editorial, entre otras. Hoy en día, incluso, se puede prescindir de un diseñador gráfico para que una empresa diseñe su propio logo, su propia web, carteles promocionales, presentaciones, entre otros. Existen aplicaciones y templates (por ejemplo, Canva) que facilitan la manipulación de imágenes y texto, con vectores y formas prediseñadas de gran calidad que favorecen la generación de imágenes visualmente aceptables. Por ello, desde esta óptica, se pueden identificar nuevas propuestas educativas con ofertas de posgrado, incluso de instituciones emergentes, que de alguna manera comienzan a disolver el pasado de gran tradición en la formación.

Respecto a la búsqueda de métodos universales para emprender el proceso de diseño, podemos tomar el caso del Design Thinking (DT) como signo de su disolución. El DT es quizá la tendencia que más polémica ha generado en las áreas del diseño, y no parece que en algún momento vaya a lograr un consenso. Para algunos es una perspectiva, para otros es un método, para otros un proceso (Esqueda et al., 2017). Asimismo, existen referencias en donde a veces se presenta como proceso de cinco pasos y a veces de seis o siete; además, los nombres de cada etapa del proceso no suelen coincidir. Sin embargo, el DT es uno de los procesos más exitosos en el ámbito empresarial 


\begin{tabular}{|c|c|c|c|}
\hline \multicolumn{4}{|c|}{ Cuadro 1. Síntesis de las características de los tiempos líquidos } \\
\hline Tiempo & Colectividad & Extraterritorialidad & Des-predeterminación \\
\hline $\begin{array}{c}\text { Énfasis en el aspecto tempo- } \\
\text { ral y transitorio y rechazo a } \\
\text { lo definitivo y permanente. }\end{array}$ & $\begin{array}{c}\text { Énfasis en las formas } \\
\text { compartidas y colectivas, } \\
\text { rechazo a la individualidad. }\end{array}$ & $\begin{array}{c}\text { Énfasis en las prácticas des- } \\
\text { territorializadas y rechazo al } \\
\text { arraigo del espacio físico. }\end{array}$ & $\begin{array}{c}\text { Énfasis en la flexibilidad } \\
\text { y adaptación y rechazo a } \\
\text { pautas preconfiguradas. }\end{array}$ \\
\hline
\end{tabular}

Fuente: Elaboración propia (2020)

a pesar de su falta de solidez o, en otras palabras, de su estado líquido. La disolución del pasado en este caso es visible por el abandono de una búsqueda de consenso, de un método idóneo, de la mejor forma de hacer las cosas o el proceso de diseño. Todo ello empieza a disolverse y, en cambio, hay una pluralidad de perspectivas, un concepto sujeto a distintas interpretaciones, 101 métodos del diseño (Kumar, 2013) o más y varios procesos de diseño.

Sin embargo, quizá sea difícil para algunos miembros de la comunidad del diseño abandonar la idea de que existen verdades universales, como el Consejo de Diseño Británico que aún en 2007 emprendió una investigación para encontrar el proceso de diseño idóneo (The Design Council, 2007). Para las comunidades más sólidas será un reto aceptar que aquello que una vez se declaró como esencial no lo sea o que incluso no se pueda llegar determinarlo; pero, para otros, la posibilidad de abandonar los manifiestos, los estatutos, las visiones consolidadas, representa una oportunidad de innovación para las disciplinas creativas y sus prácticas.

\section{El estado líquido de las cosas}

A partir de una investigación documental, se presentan aquí las principales características de los tiempos líquidos (Cuadro 1) identificadas por Bauman y complementadas con la revisión de otros autores que han abonado a dicha perspectiva. Esta sistematización persigue dos objetivos particulares: primero, conocer los atributos de las sociedades líquidas; segundo, tomarlas como referencia para revisar prácticas del diseño actuales y reflexionar sobre las posibilidades de su fluidez.

\section{El tiempo}

Este es uno de los aspectos más importantes para comprender la metáfora de la fluidez y cómo proyectarla a las prácticas actuales. Al considerar el tiempo de los fluidos, se vuelve visible que estos no permanecen con la misma forma más que por instantes. El tiempo se refiere a una capacidad de adaptación que a la vez es transitoria y a un movimiento constante. "Los líquidos, a diferencia de los sólidos, no conservan fácilmente su forma [...] no se fijan al espacio ni al tiempo" (Bauman, 2003, p.3).

A pesar de que Bauman reflexionaba sobre la aparición de formas constantemente temporales apenas a principios del siglo XXI, se pueden identificar prácticas sociales que se están modificando de acuerdo a su temporalidad. Las nuevas generaciones han estado manifestando comportamientos distintos que sugieren una mayor liquidez en ciertas prácticas específicas. Los millennials -llamados así porque aquellos de mayor edad alcanzaron su adultez cerca del cambio de milenio, es decir, nacidos entre 1980 y 1999- representan una cuarta parte de la población en México (Pérez, 2019). Son personas dedicadas a vivir en el presente, por lo que buscan la gratificación instantánea y no están dispuestos a dedicar todo su tiempo y esfuerzo a un trabajo, sino que desean un balance entre trabajo y diversión (Abbot, 2019). Además, es una generación que creció junto con la tecnología, por lo que son nativos digitales asiduos a utilizar multipantallas (computadoras, videojuegos, tablets, teléfonos celulares) y por ello también tienen la habilidad para desarrollar varias tareas a la vez, es decir, el multitasking (Gutiérrez-Rubí, 2014). 
La generación millennial ya representa un 35\% de la fuerza laboral en Estados Unidos, por lo que los cambios en su comportamiento están impactando en formas de trabajo y consumo (Fry, 2018). Cada vez es más común que se involucren en actividades por contratos temporales, lo que los lleva a cambiar de trabajo cada 28 meses (Universia, 2017). Aunque ya tengan un compromiso laboral, el 50\% de ellos manifiesta seguir buscando empleo (Villafranco, 2018). Además, muestran un gran desinterés por adquirir una vivienda, pues representa un compromiso sólido a largo plazo, vivir por mucho tiempo en el mismo lugar y adquirir una gran deuda con una misma institución. En cambio, prefieren la renta compartida y así destinar ingresos para entretenimiento y viajes (Dominguez, 2016). La solidez de la vivienda propia está siendo suplantada por la liquidez de la vivienda temporal para mantener abierta la posibilidad de mudarse un lugar más interesante o incluso cambiar de ciudad o país.

"Los fluidos no conservan una forma durante mucho tiempo y están constantemente dispuestos a cambiarla" (Bauman, 2003, p.8). Es común encontrar en la mentalidad de esta generación que la vivienda, el trabajo, las actividades recreativas e incluso las relaciones sociales sean concebidas como aspectos temporales, dispuestos siempre a cambiarlas. Estas son solo algunas de las tantas manifestaciones que podrian enlistarse para dar mayor visibilidad al cambio de temporalidad en la contemporaneidad líquida.

Por eso mismo, el tiempo es uno de los elementos centrales del concepto de liquidez, pues la forma que adquiere el líquido es solo por un momento y luego cambiará. Los líquidos "fluyen, se derraman, salpican, gotean, chorrean" (Bauman, 2003, p.8), a diferencia de los sólidos. Por lo tanto, resulta de suma importancia tomar en cuenta las características que en la actualidad hacen del proceso de diseño un aspecto transitorio o temporal.

El tiempo líquido en el diseño puede significar que el proceso de diseño no permanezca estable durante mucho tiempo, por eso mismo, se puede observar una gran proliferación de métodos y herramientas para complementar las distintas fases del proceso de diseño (Kumar, 2013). Asimismo, también se puede identificar una falta de consenso -aspecto que tampoco parece importar demasiado- sobre ciertas tendencias del diseño, como el polémico design thinking (Esqueda et al., 2017), pues constantemente están cambiando su forma.

Los mismos objetos - productos de los distintos procesos de diseño- han mostrado también gran capacidad de adaptación y una naturaleza transitoria. Mobiliario, espacios e imágenes están buscando cómo incorporar aspectos flexibles a su diseño, de manera que pueda transitar de un estado a otro para mantenerse vigente. Rudinei Kopp (2013) logra de manera certera hacer visible este fenómeno en la identidad de ciertas marcas que muestran una gran predilección por el cambio, adaptándose a acontecimientos, festividades, promociones, entre otras. La identidad de marca, uno de los aspectos más sólidos en empresas tradicionales, ha comenzado a mostrar rasgos de ser uno de los más cambiantes. Por eso mismo la capacidad de adaptación o flexibilidad se ha convertido en un valor de las marcas contemporáneas.

Además, se destaca que la capacidad transitoria de los líquidos está relacionada con su liviandad o ligereza, pues "cuanto menos cargados nos desplacemos, más rápidos será nuestro avance” (Bauman, 2003, p. 8). Esta ligereza nos ayuda a entender que un proceso creativo más ligero, es decir, sin tantos métodos, herramientas o estudios, tendrá una mayor capacidad de fluir y adaptarse a necesidades de distintos proyectos. Así, la ligereza del proceso de diseño representa una fortaleza en sí misma para la disciplina y una gran ventaja para hacer frente a problemas actuales, pues según Muratovski (2015), "la adaptabilidad del diseño a entornos en constante evolución es lo que hace que su práctica sea relevante en tiempos de cambio" (p. 119).

\section{La colectividad}

La fluidez también se ha manifestado en los vínculos que se generan entre los individuos (Bauman, 2003). 
Se han borrado las fronteras anteriores y ahora se conectan de nuevas y distintas maneras, generando otras formas de colectividad. Ahora "la sociedad se ve y se trata como una red, en vez de como una estructura" (Bauman, 2013, p.9). Los avances tecnológicos en materia de información y comunicación han colaborado también a estos cambios, pues "la conectividad incrementada de la sociedad actual está logrando disolver formas de organización social tradicionales" (Manzini, 2017, p.188). Esto se puede ver en distintas prácticas sociales. La pandemia en el año 2020 causada por el SARS-CoV-2, un virus que afecta principalmente las vías respiratorias, aceleró el desarrollo de nuevas formas laborales a través de la tecnología. Debido a la orden de confinamiento obligatorio en varios países, las empresas buscaron otras formas de trabajo colaborativo, lo que resultó que aplicaciones que permiten videollamadas grupales, como Zoom y Teams, ganaran popularidad y tuvieran una alta demanda en entornos laborales (O'Flaherty, 2020), así como en la educación a distancia junto con otras tecnologías.

Asimismo, las relaciones de amistad o relaciones de pareja pueden existir gracias a la vida a través de internet. En la actualidad existen cerca de 8.000 sitios y aplicaciones para citas en línea, en las cuales han participado 50 millones de personas (Matthews, 2018). Además, el 20\% de las relaciones actuales exitosas empezaron en línea (Matthews, 2018) y el 69\% de las personas que se encuentra en una relación reconoce incluso hablar más con su pareja cuando están a distancia (Schmall, 2018).

Al mismo tiempo, surgen otras formas de consumo entre las que se encuentra la sharing economy, llamado también consumo compartido -collaborative consumption-, que refleja un claro desinterés por poseer productos. Algunos autores han definido la economía compartida como una "actividad de-igual-a-igual, [peer-to-peer], de obtener, dar, o compartir el acceso a productos y servicios a través de comunidades o plataformas en línea" (Hamari, Sjöklint y Ukkonen, 2016).
Así, una persona poseedora de herramientas, cámaras fotográficas, equipo para acampar, automóviles, entre otras cosas, simplemente renta o incluso presta de manera gratuita el equipo a otra persona dentro de una comunidad en línea. Esta forma colectiva surge dado el hecho de que $80 \%$ de los artículos que se poseen en una casa se utilizan una sola vez al mes (Tabcum, 2019). Esta forma de economía, en esencia, busca privilegiar el acceso más que la posesión de bienes y servicios, y gracias a ello empresas como Uber, Airbnb y Netflix han logrado encontrar nichos de mercado muy provechosos (Rinne, 2019).

Con Internet más que adaptado a la vida cotidiana, los negocios "no tienen opción más que comunicarse en tiempo real con sus stakeholders en un foro definido por las siempre cambiantes tecnologías digitales" (Muratovski, 2015, p. 120). Las prácticas del diseño, insertadas cada vez más en las prácticas comerciales, no han sido ajenas a las nuevas formas de colectividad. Entre los aspectos más visibles se puede mencionar que cada vez es más aceptada la idea de que los procesos de diseño sean colectivos, manifestándose en tendencias como el codiseño o el diseño participativo (Lee, 2008; Manzini y Rizzo, 2011), que tienen la intención de involucrar a todos aquellos que afectan y son afectados por un problema con el fin de buscar soluciones de manera conjunta.

Cada vez va quedando más lejos la idea de un gurú del diseño que da consultoría a distintas empresas, manifestándose más bien nuevos equipos de diseño internos. Asimismo, la visión del diseño como un ente aislado de la dinámica organizacional está siendo superada, pues ahora se privilegia la multidisciplinariedad por encima de la especialización. Por otro lado, las herramientas empleadas para diseñar también han sufrido cambios, pues ya existe software especializado, pero de uso libre, es decir, que puede ser descargado y manipulado de forma gratuita. Se disuelve así la hegemonía de las grandes empresas consolidadas en el comercio herramientas computacionales. 


\section{Extraterritorialidad}

Con la llegada de la telefonía móvil con acceso a Internet quedó aún más clara la disolución de los espacios físicos (Bauman, 2003, p.16). Una persona puede realizar una transacción bancaria, que es una de las instituciones más sólidas, desde un auto en movimiento. La disolución del espacio significa también otras formas de organización laboral. Con la conectividad ya mencionada, todo un equipo, por ejemplo, de cinco personas, puede interactuar y trabajar aún y cuando cada uno de ellos se encuentre en distintos países. Lo mismo sucede con las relaciones laborales, en las que el trabajo se ha vuelto cada vez más móvil, significando que cerca del 50\% de las personas pasen la mitad del día fuera de la oficina (Higginbottom, 2018). Estas nuevas formas laborales implican también horarios flexibles y trabajar de forma remota, prácticas que se ha incrementado en los últimos años. En Estados Unidos, por ejemplo, un 31\% de la población trabaja de manera remota de cuatro a cinco días a la semana (Chokshi, 2017).

Actualmente existen poco más de 19,000 lugares de coworking en el mundo (Stevanovic, 2020), espacios en los que se puede rentar un escritorio o toda una oficina por día, semana, mes o año. Así, las oficinas de algunas empresas se han vuelto líquidas y se reúnen en espacios -que son compartidos con otras empresasun par de veces a la semana o al mes. La empresa se libera de contratar servicios a largo plazo como agua, luz, teléfono e Internet.

Además, hoy el consumidor puede adquirir un artículo de otro país directamente del productor, desde la comodidad su hogar, lo que significa una disolución o reconcepción del territorio. Algunos estudios afirman que para el 2021 el 14\% de las ventas al menudeo serán a través del comercio electrónico (Grant, 2018), cifra que seguirá creciendo en los siguientes años. Tan solo en
México, el 80\% de los usuarios de internet ha realizado alguna compra en línea en el último año (Notimex, 2018). Esta cifra cobra aún más relevancia si se estima que el 63\% de los mexicanos tiene acceso a Internet y para el 2021 será 71.9\%, penetración que está incluso por encima de otros países latinoamericanos como Colombia y Brasil (Notimex, 2018).

Así, las prácticas sociales dejan de depender del territorio, siendo posible realizar actividades como trabajar, hacer compras en el supermercado, en tiendas de ropa, farmacias, transacciones bancarias, ver una película, escuchar un concierto en el momento en que sucede, entre muchas otras actividades en las que anteriormente era imposible hacerlo sin acudir a un espacio físico.

La desterritorialización del diseño ha representado una gran ventaja para quienes se desempeñan como freelance. Un estudiante puede armar una página web o tener su perfil como diseñador en redes sociales o en redes especializadas para mostrar su trabajo. En otras palabras, de manera individual o en grupo se puede montar un "despacho de diseño" sin necesidad de un espacio físico. De esa manera, un diseñador local puede competir con otro en cualquier parte del mundo. Asimismo, las empresas del primer mundo pueden buscar talento nuevo y en ocasiones más barato contactando perfiles con poca experiencia, pero que demuestran un estilo propositivo para sus intereses de negocio. De igual manera, existen actualmente cada vez más formas laborales en las que un diseñador puede estar contratado, ya sea de tiempo completo, de medio tiempo o por proyecto para una empresa. Dado que la colectividad y la desterritorialización suelen ir de la mano, se ha hecho posible también la colaboración con otros diseñadores del mundo, o la pertenencia a grupos de diseño a nivel global que permiten participar en todo tipo de proyectos, desde causas sociales hasta aquellos comprometidos con el medio ambiente. 


\section{Des-predeterminación}

La disolución de aspectos predeterminados o preconfigurados surge debido a que las pautas llegan a ser demasiadas, al mismo tiempo que se contradicen entre sí (Bauman, 2003, p.13). El desarrollo de prácticas sin pautas predeterminadas ha llevado también a la "era de la instantaneidad" (p.20) en la que se otorga valor a lo nuevo, lo rápido y al momento. Cuando se opera en un mundo en transformación rápida y profunda, cada sujeto tiene constantemente que redefinir sus objetivos e inventar nuevas formas de hacer las cosas. Por eso mismo, hoy en día ha surgido la necesidad de las personas de rediseñar su vida todos los días (Manzini, 2017, p. 188), redefiniéndose y diseñándose a sí mismos a cada instante.

Quizá una de las formas más visibles de esta característica se da en las redes sociales, a través de las cuales las personas pueden redefinir su identidad cambiando la información e imágenes de su perfil virtual si así lo desean. Al mismo tiempo, pueden transmitir al mundo el instante exacto que viven mediante el clic en un botón del teléfono móvil. Tan solo en Instagram existen 500 millones de usuarios activos diariamente, de los cuales el 89\% están fuera de los Estados Unidos (Aslam, 2020). En esta red, el usuario puede subir fotografías y videos efímeros que duran activos solo 24 horas. Este tipo de publicaciones se denominan Historias y cuentan con 400 millones de usuarios al día (Aslam, 2020). En otras palabras, una persona puede publicar contenidos distintos para definirse a sí mismo, y esa "personalidad" solo durará 24 horas. Además, con la llegada de Instagram TV (IGTV), que ofrece la posibilidad de crear videos más largos que 30 segundos y de transmitir en vivo, el teléfono móvil se convierte en un canal abierto, en blanco, sin predeterminaciones, para que los usuarios digan lo que quieran en el momento en que lo deseen.

Una des-predeterminación significa un abandono de los métodos en las prácticas del diseño. Esto ya comienza a ser visible en la proliferación de toolkits y libros de mé- todos (Kumar, 2013; Martin y Hanington, 2012; Stickdorn y Schneider, 2012; Digital Society School, s. f.; IDEO. org, s. f.; Dinngo, s. f.) para todo tipo de ocasiones. Los autores buscan en estas obras, a través de su catálogo, mostrar casos de estudio exitosos y los métodos que se diseñaron para dichos casos, pero en "un mundo fluido todo se convierte en algo transitorio, modificable y experimental [...] todas las formas que aparecen en él son inestables por definición" (Manzini, 2017, p. 188). Por lo tanto, el éxito de un método en un contexto particular no significa que vaya a dar resultados favorables en otro.

En la práctica del diseño comienza el abandono de la predeterminación de los métodos a utilizar, sustituyéndolo por su desarrollo en el instante mismo en el que se diseña. Abandonar las ideas preconcebidas sobre qué métodos y técnicas utilizar para iniciar el proceso de diseño significa acercarse al problema con la mente en blanco, darse el tiempo de conocer el contexto y sus relaciones. En cierta medida, una des-predeterminación del proceso de diseño será un acercamiento más honesto entre todos los involucrados. El diseñador, entonces, toma conciencia de que un método, por más exitoso que sea en un contexto particular, no puede garantizar que así lo será en otro. Sin duda este aspecto representa una tarea difícil para la práctica del diseño, que la mayoría de las veces debe responder a dinámicas aceleradas, pero, sin duda, diseñar la forma de acercamiento como estado fluido de la práctica es quizá uno de los aspectos más esenciales de esta disciplina. En otra palabras, surge la paradoja del diseño: su estado de liquidez es el aspecto más sólido que existe.

\section{Diseño líquido: la evolución de la práctica}

Sin caer en el desarrollo de un manifiesto inamovible, se presentan aquí siete rasgos identificados hasta ahora en las prácticas del diseño como signos de su estado líquido, a manera de una invitación tentadora 
Figura 1. Prácticas del diseño en estado líquido

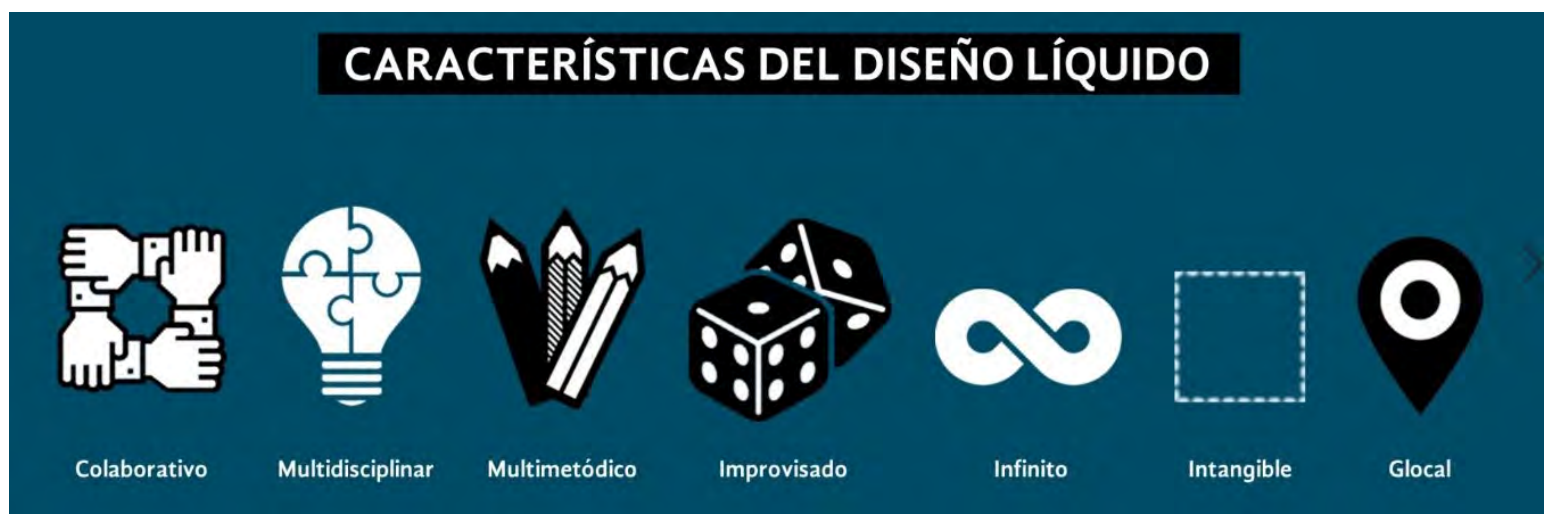

Fuente: Elaboración propia (2020)

para motivar la reflexión (Figura 1). Asimismo, a través de estas siete características se pretende mostrar las posibilidades del diseño líquido para la expansión de la práctica profesional.

\section{El diseño líquido es colaborativo}

La tendencia en las prácticas del diseño es que se lleve a cabo entre varias personas, surgiendo tendencias importantes como la cocreación. Además, hay una creciente participación tanto del cliente como del usuario final de los diseños, en perspectivas como el diseño participativo. La colaboración no es una tendencia exclusiva del diseño, sino de las prácticas al interior de las organizaciones en las que se involucran distintas profesiones. El valor de borrar las jerarquías ha llevado a derrumbar cubículos, divisiones y fronteras físicas para que el mismo espacio sea el promotor de la colaboración. Aunque no en todos los casos haya funcionado, se destaca la obsesión de las áreas administrativas por promover la colaboración entre sus miembros (Gaskel, 2018).

Para el diseño líquido, la colaboración implica salir de la idea del diseñador que todo lo ve, para involucrar más puntos de vista que impacten en una visión más amplia del proyecto, incluso si los colaboradores cambian dependiendo de la fase del proceso de diseño. El objetivo es eliminar todos los puntos ciegos para el diseñador, buscando obtener una visión de $360^{\circ}$. El diseño líquido es social, colectivo e incluyente, se lleva a cabo por un grupo de personas que comparten tanto responsabilidad como autoría.

\section{Multidisciplinar}

En el momento en que se promueve la colaboración, esto significa también una apertura a otras disciplinas distintas al diseño. En la práctica existen disciplinas que se pueden considerar afines como la mercadotecnia, la comunicación, algunas ingenierías, las artes, entre otras. Sin embargo, cuando se habla de una participación multidisciplinar, las fronteras se borran. Una verdadera práctica multdisciplinar implica involucrar perspectivas que aparentemente no tendrían relación, desde las ciencias básicas como la biología y la química -las cuales pueden colaborar en el desarrollo de materiales más amigables con el medio ambiente- hasta las ciencias sociales como la antropología y la etnografía -cuyo vínculo ya ha mostrado dar grandes frutos y gestado nuevas tendencias, como el diseño centrado en el humano (IDEO.org, 2011).

Además, con el objetivo de contar con una visión holística, la práctica multidiscipinar ha mostrado tener impacto en el desarrollo económico, pues promueve la formación de clústeres a través de los cuales las empresas se vuelven más competitivas (The Design Council, 2018). El diseño líquido promueve la interacción de varias disciplinas, convirtiéndose en el punto de convergencia, de enfrentamiento y negociación.

\section{Multimetódico}

El método ideal para el proceso de diseño en estado líquido no existe. Esto significa que todos los métodos propuestos para guiarlo son válidos y a la vez inválidos, pues depen- 
derá de cada proyecto. La racionalidad técnica heredada del pensamiento moderno aún busca identificar las fases o etapas del proceso de diseño. Por ejemplo, el Consejo de Diseño Británico (The Design Council, 2007) hizo una consulta a 11 empresas caracterizadas por su práctica innovadora en diferentes ramos de la industria, con el objetivo de reconocer aquellas actividades comunes en cuanto al proceso de diseño. Aunque este Consejo llega a la conclusión de cuatro fases, lo que deja ver en su reporte es que cada organización tiene un proceso distinto, lo que implica que no existe el proceso y método ideal para el diseño y para la innovación.

No es casual que en la actualidad se sigan proponiendo métodos y técnicas que buscan colaborar en la mejora del proceso de diseño, como ya se expuso anteriormente. Sin embargo, es de suma importancia recalcar que no existe un método, técnica y proceso idóneo que sea adaptable a todas las problemáticas sociales, así como el hecho de que uno sea exitoso no garantiza que lo siga siendo cada vez que se aplique, aunque el contexto sea idéntico. La práctica del diseño en tiempos de cambio debe promover la adaptabilidad, aspecto que implica que se utilice uno o varios métodos desde una perspectiva abierta, que permita en algún momento desecharlos y tomar otros, incluso durante del desarrollo del proyecto. El diseño líquido no tiene un método, sino que sabe reconocer aquellos que son necesarios para el problema que enfrenta.

\section{Improvisado}

El concepto de improvisación ha sido comúnmente utilizado en sentido peyorativo, aludiendo a la falta de preparación. Sin embargo, en este punto refiere al abandono de las predeterminaciones. Si no existe el método o combinación de métodos y técnicas idóneos para emprender el proceso de diseño, como recalca el punto anterior, entonces el equipo de diseño no tendría por qué acercarse a un problema con una serie de pasos ya predispuestos. Un proceso de diseño abierto implica que no necesariamente deba comenzar por un estudio de usuarios, como lo determinan algunos toolkits en los que se requiere una fase de descubrimiento. La no-predeterminación podría incluso iniciar con el desarrollo de prototipos y de ahí pasar a la consulta de usuarios, o cualquiera que sea la ruta que se diseñe para ese contexto en particular.

Lo improvisado no necesariamente significa falta de preparación o de profesionalismo, sino que significa el abandono de prejuicios. Además, si se incluyen aspectos como los mencionados anteriormente, el proceso de diseño contará con un abanico de métodos al alcance de un equipo multidisciplinario dispuestos a trabajar de manera colaborativa. El diseño líquido no tiene pasado ni futuro, sino que se reinventa en el instante en que se practica.

\section{Infinito}

La práctica iterativa del proceso de diseño es un aspecto cuya mención cada vez se vuelve más recurrente (Kumar, 2013; IDE0.org, 2011). Este aspecto resalta la capacidad de la práctica de mejorarse a sí misma. Desde este punto de vista, el proceso de diseño es una práctica continua que cada vez que inicia un nuevo ciclo tiene por objetivo identificar áreas de aplicación y, por lo tanto, de mejora. Además, con cada nueva vuelta que iterativamente se acciona, pueden integrarse nuevos colaboradores al proceso que ayudarán a observar aspectos que habían pasado desapercibidos anteriormente, logrando que el proyecto continúe en su evolución. De esta manera, el campo de acción y la forma de proceder podrían ser siempre distintas.

Así el proceso de diseño se mantiene siempre en estado líquido, abordando aspectos que involucran un entramado de problemas que también cambian con cada nuevo ciclo del diseño. El diseño líquido implica reconocer que el proceso está siempre abierto, es decir, aceptar que no tiene final claro y definido, y que construir un reporte de evaluación como última etapa representa al mismo tiempo un nuevo punto de partida. 


\section{Intangible}

La profesión del diseño se ha expandido más allá de producir imágenes, objetos y espacios, desarrollando la capacidad de diseñar sistemas, estrategias y experiencias (Muratovski, 2015, p.138). Esto significa un cambio de énfasis en el que las actividades y productos del diseño no están condicionados a la destreza manual del diseñador. El diseño líquido es intangible dado que no necesariamente desarrolla objetos como resultado del proceso de diseño. Los productos finales pueden ser tan complejos que requieran la activación de una serie de estrategias y de un equipo de personas para llevarlas a cabo.

La práctica de diseñar sin manos supone un abandonar la búsqueda del domino de la técnica formal para desarrollar un pensamiento analítico y estratégico, a través del cual se puedan enfrentar problemas complejos. Una sociedad en proceso de licuefacción requiere un abordaje desde esta perspectiva, pues los retos que se le presentan demandan un trabajo colaborativo, multidisciplinar, multimetódico y analítico, entre otros aspectos. Gracias a esta expansión del campo de acción del diseño, los profesionales de la disciplina han encontrado oportunidades de crecimiento al interior de las organizaciones, en las cuales ya no necesariamente se desempeñan como maquetadores detrás de un monitor, sino como estrategas que participan en la toma de decisiones (Hargadon, 2005). El diseño líquido no produce cosas sólidas, sino sistemas que también se encuentran en estado líquido.

\section{Glocal}

La práctica del diseño des-territorializado representa un derrumbe de fronteras en las que aspectos globales interactúan con los locales y viceversa, borrando jerarquías, límites. En ese sentido, prácticas particulares y locales representan un valor que puede tener participación a nivel global. Estas interaccionas han sido reconocidas como glocalización (Robertson, 1992), aunque el concepto de glocal tenga diferentes interpretaciones (Roudometof, 2015).
Esta interacción puede manifestarse de diversas maneras, por ejemplo, la práctica colaborativa se puede dar entre profesionales que radiquen en ciudades distintas, pero que la visión particular de su contexto local pueda aportar al desarrollo global de proyectos.

Desde el diseño líquido, la práctica profesional llamaría a comprender las situaciones globales aun y cuando los proyectos son locales, pues su alcance no está condicionado por el territorio. Así, un diseñador freelance puede competir con una agencia de diseño al mismo nivel, o incluso una agencia que radica en una ciudad pequeña competirá con otra que tiene filiales en distintas partes del mundo. El diseño líquido diluyen las jerarquías, las fronteras y el espacio, trayendo como consecuencia un mundo más conectado, pero a la vez más competitivo.

\section{El reto pedagógico de los procesos creativos líquidos}

Se han presentado siete rasgos del diseño líquido, es decir, de cómo las prácticas de la modernidad líquida se han manifestado en la profesión del diseño. Se debe tener en cuenta que los que aquí se presentan probablemente no son todos los que se puedan identificar, así como tampoco son permanentes. Mucho menos deben ser vistas como condicionantes para una práctica fluida. En cambio, son presentados como signos de que la práctica está cambiando, ya sea que aparezca uno más frecuente que otro o todos al mismo tiempo. Son características que a su vez se encuentran en estado líquido, con la posibilidad de cambiar, adaptarse, escurrirse o evaporarse. Su presencia en el quehacer profesional del diseño es a su vez un llamado a mirar con otros ojos los procesos de formación y las instituciones en las que estos se dan.

Ante una sociedad que comienza a diluirse en todas sus esferas sólidas, formar profesionales que puedan hacer frente a los nuevos escenarios puede convertirse en uno de los grandes retos del siglo XXI. No solo porque implica el desarrollo de habilidades que permitan enfrentar la incertidumbre (López-León, 2018b), o por la 
resistencia que pueda existir de la comunidad académica (Das, 2012), sino también porque las mismas instituciones educativas pueden ser las estructuras más sólidas y resistentes hacia los procesos líquidos. La gran mayoría de las escuelas aún continúa trabajando por medio de estructuras y métodos de la edad industrial (Phillip citado en McWilliam y Dawson, 2008b).

Con ello, se pueden identificar muchos aspectos de la educación actual que no han cambiado por muchos años, como una clara jerarquía piramidal en la organización, un comando y control claros que regulan calendarios predeterminados, cursos fragmentados en especialidades disciplinares, impartición de clase en salones a los que asisten treinta o más estudiantes, los cuales siempre están sentados en filas de escritorios mirando al pizarrón (Phillip citado en McWilliam y Dawson, 2008b). Además, en estas estructuras piramidales, los docentes son autoridades de contenido (McWilliam y Dawson, 2008b), es decir, los estudiantes aún continúan accediendo a los contenidos de aprendizaje a través de los profesores. Sin embargo, dado que en otras áreas la fluidez ha alcanzado distintas prácticas sociales, el crecimiento económico ha manifestado requerir sistemas abiertos, mientras que las escuelas continúan siendo sistemas cerrados.

Los mismos aspectos detectados en este trabajo sobre la modernidad líquida de Bauman aplican también para lograr una mayor apertura de las instituciones educativas. Aunque dichas características no serán expuestas en amplitud como se ha hecho en torno al diseño, sí resulta fundamental destacar que una de las áreas que deberían derretirse en la práctica educativa son las jerarquias y prácticas didácticas hegemónicas en las que el docente busca controlar el aprendizaje de los estudiantes. De acuerdo con McWilliam y Dawson (2008a, p.8), el aprendizaje es una actividad social, mismo aspecto que Csikszentmihalyi (1997) destaca como importante para el desarrollo creativo. Por eso mismo, es necesario un cambio de modelo educativo, pasando de un modelo de transmisión del conocimiento a un modelo socialmente-centrado en el que el conocimiento y aprendizaje se desarrolle de manera colaborativa, enfoque aún muy incipiente en las universidades en México.

McWilliam y Dawson (2008a) destacan que, similar al comportamiento de una manada, cada individuo contribuye de manera colectiva para lograr "objetivos de aprendizaje compartidos" (p. 8). Esta relación de colectividad puede promover el desarrollo de nuevas formas de aprendizaje y aprovechamiento del trabajo colaborativo para los procesos creativos, y se pueden identificar algunas características:

- Conectividad: no necesariamente tecnológica, definida como una red local que comparta intereses comunes.

- Cocreación: la posibilidad de desarrollar producciones auténticas a partir de la sinergia entre sus miembros.

- Liderazgo colectivo: un entorno que comparta responsabilidades y permita definir de manera colectiva los objetivos por alcanzar.

- Remoción de inhibidores: un entorno que promueva la participación de los miembros del equipo y permita sobreponerse a los obstáculos.

- Permiso para cometer errores: un entorno que acepte desde un inicio que los participantes en algún momento cometerá errores, para así aceptarlos y aprender de ellos (McWilliam y Dawson, 2008b).

Cada una de estas características representa un reto en distintos niveles al interior de las instituciones que requieren todo el compromiso de la comunidad académica para acercar la formación profesional a la acelerada fluidez del siglo XXI. 


\section{Conclusiones}

La actualidad del discurso de Bauman respecto a los aspectos aquí identificados son un signo de que la fluidez de las esferas sociales no ha sido superada. A partir de esta revisión es posible observar que, en efecto, las instituciones instauradas en la modernidad están siendo diluidas. Por ejemplo, la London School of Architecture ${ }^{2}$ es una universidad que no tiene un edificio sede, ni aulas, ni clases. Los estudiantes de primer año realizan prácticas itinerantes en distintas empresas relacionadas con la arquitectura. No hay asignaturas, no hay principios básicos o largas horas de dibujo al natural. Esta universidad sin paredes cuenta con una red de casi 30 empresas del área de arquitectura en las que los estudiantes realizan prácticas $\mathrm{y}$, dependiendo del área de interés o experiencia necesaria, van cambiando de empresa en empresa. Además, la escuela cuenta con el apoyo del Design Museum en Londres para fungir como punto de reunión entre arquitectos invitados y estudiantes-practicantes para conferencias magistrales. Sin duda, este es un gran ejemplo de una escuela de diseño en estado líquido. ${ }^{3}$

La práctica del diseño no debe verse ajena a dichos cambios, por eso mismo, este texto se propone como reflexión para las disciplinas del diseño y como una invitación a mirarse a sí mismas y reconocer cómo estos cambios están impactando de manera positiva en su quehacer. Por lo tanto, esta invitación es también a abandonar el miedo a perder la seguridad de la disciplina por la obsesión de las formas sólidas, y a recordar que, en sus inicios, también el diseño representó la disolución de ciertas prácticas que ya no representaban ningún valor para aquellas que en su momento eran contemporáneas.

Se identifican siete características del diseño en estado líquido como propuesta para mirar nuevas prácticas al interior de la disciplina y reconocer tendencias. Así, un diseñador podría expandir su campo de acción y desarrollar estrategias que lo ayuden a desempeñar- se en un mundo cada vez más competitivo. Al mismo tiempo, los rasgos que se discuten aquí son también una invitación para la reflexión y un punto de partida a reconocer estos, otros y nuevos campos del diseño.

Finalmente, el presente documento reconoce que el mayor de los retos es para la comunidad académica, pues al estar construida por un pensamiento sólido-moderno, abandonar las estructuras que la han definido por tanto tiempo y que han influido en su quehacer cotidiano debe ser uno de los más grandes desafíos. Sin embargo, si el presagio de Bauman es correcto, la fluidez de las nuevas prácticas terminará por disolver hasta los cimientos más sólidos de nuestra sociedad.

\section{Referencias}

Abbot, L. (2019, mayo 8). 11 Millennials' Traits You Should Know About Before You Hire Them. Linkedin Talent Blog. Recuperdo el 9 de septiembre de 2020 de https://business.linkedin.com/ talent-solutions/blog/2013/12/8-millennials-traits-you-shouldknow-about-before-you-hire-them

Aslam, S. (2020). Instagram by the Numbers: Stats, Demographics Et Fun Facts. Recuperado de https://www.omnicoreagency.com/ instagram-statistics/

Barton, G. (2015). Architecture, teaching the future / future of teaching. En R. Vande Zande, E. Bohemia, y I. Digranes (Eds.), Learn $x$ Design. Proceedings of the $3^{\text {rd }}$ International Conference for Design Education Researchers (pp. 347-365). Aalto, Finlandia: Aalto University.

Bauman, Z. (2003). Modernidad Líquida. México D. F., México: Fondo de Cultura Económica.

Bauman, Z. (2013). Tiempos Liquidos, vivir en una época de incertidumbre. México D. F., México: Tusquets.

Berman, M. (2006). Todo lo sólido se desvanece en el aire. La experiencia de la Modernidad. México D. F., México: Siglo XXI.

\section{2:: เwww.the-Isa.org}

3:: Gemma Barton (2015) realizó entrevistas a personalidades que han desarrollado nuevas propuestas educativas como la que aquí se menciona. Se recomienda consultar su trabajo para conocer otras. 
Csikszentmihalyi, M. (1997). Creativity: Flow and the psychology of discovery and invention. New York, NY: Harper Adams.

Chokshi, N. (2017, febrero 15). Out of the Office: More People Are Working Remotely, Survey Finds. The New York Times. Recuperado de https://www.nytimes.com/2017/02/15/us/remote-workers-workfrom-home.html

Das, S. (2012). On two metaphors for pedagogy and creativity in the digital era: liquid and solid learning. Innovations in Education and Teaching International, 49(2), 183-193

Digital Society School. (s. f.). Toolkits. Recuperado de https://toolkits. dss.cloud/design/

Dinngo. (s. f.). Design Thinking Toolkit. Recuperado de https://designthinking.es/inicio/herramienta.php?id=60\&fase $=$ idea

Dominguez, F. (2016, enero 22). 5 Gastos que los millennials no quieren hacer. Forbes. Recuperado de https://www.forbes.com.mx/5-gastosque-los-millennials-no-quieren-hacer/

Esqueda, R., López León, R., Martínez de la Peña, A., Rivera, A., Rodríguez, L., Tapia, A., Tiburcio, C.... Villalobos, S. (2017). ¿Design Thinking? Una discusión a nueve voces. México D. F., México: Ars Optika.

Fry, R. (2018, abril 11). Millennials are largest generation in the U.S. labor force. Pew Research Center. Recuperado el 10 de septiembre de 2020 de https://www.pewresearch.org/fact-tank/2018/04/11/ millennials-largest-generation-us-labor-force/

Gaskel, A. (2018, agosto 6). How open plan offices impact collaboration. Forbes. Recuperado de https://www.forbes.com/sites/adigaskell/2018/08/06/how-open-plan-offices-impact-collaboration/\#68cc156438d0

Grant, M. (2018, agosto 14). E-commerce Set For Global Domination - But At Different Speeds. Forbes. Recuperado de https://www.forbes.com/sites/michellegrant/2018/08/14/e-commerce-set-for-global-domination/\#4a70d001bfaf

Gutiérrez-Rubi, A. (2014, diciembre 22). 6 rasgos clave de los millennials, los nuevos consumidores. Forbes. Recuperado de https://www. forbes.com.mx/6-rasgos-clave-de-los-millennials-los-nuevos-consumidores/

Hall, S., Slack, J. D., y Grossberg, L. (2016). Cultural studies 1983 a theoretical history. Durham, NC: Duke University Press.

Hamari, J., Sjöklint, M., y Ukkonen, A. (2016). The Sharing Economy: Why People Participate in Collaborative Consumption. Journal of the Association for Information Science and Technology, 67(9), 2047-2059.
Hargadon, A., (2005). Leading with Vision: The Design of New Ventures. Design Management Review 16(1), 36-39.

Higginbottom, K. (2018, junio 21). Working from home considered to be most productive workspace. Forbes. Recuperado de https:// www.forbes.com/sites/karenhigginbottom/2018/06/21/working-from-home-considered-to-be-most-productive-workspace/\#4d77cea21b67

IDEO.org. (s. f.). Design Kit. Recuperado de http://www.designkit. org/methods

IDEO.org. (2011). Human centered design. Indiana, IN: Authorhouse.

Kopp, R. (2013). Diseño Gráfico cambiante. México D. F., México: Ars Optika.

Kumar, V. (2013). 101 Design Methods: A Structured Approach for Driving Innovation in Your Organization. Hoboken, NJ: John Wiley and Sons.

Lee, Y. (2008). Design participation tactics: the challenges and new roles for designers in the co-design process. CoDesign $4(1), 31-50$.

López-León, R. (2018a). El contexto como elemento central en la generación de conocimiento del diseño y su aprendizaje: la perspectiva de Donald Schön. En R. López-León (Coord.), Contexto y Diseño: el Binomio Invisible (pp. 67-90). Aguascalientes, México: Universidad Autónoma de Aguascalientes.

López-León, R. (2018b). El diseño del futuro y la incertidumbre como reto pedagógico. En I. Carrillo (Ed.), Nuevas Vanguardias y Tendencias en el Diseño (pp. 89-111). San Luis Potosí, México: Universidad Autónoma de San Luis Potosí.

Manzini, E. (2017). Designing coalitions: Design for social forms in a fluid world. Strategic Design Research Journal, 10(2), 187-193.

Manzini, E., y Rizzo, F. (2011). Small projects/large changes: Participatory design as an open participated process. CoDesign, 7(3-4), 199-215.

Martin, B., y Hanington, B. (2012). Universal Methods of Design. Beverly, MA: Rockport Publishers.

McWilliam, E., y Dawson, S. (2008a). Teaching for creativity: Towards sustainable and replicable pedagogical practice. Higher Education, 56(6), 633-643.

McWilliam, E., y Dawson, S. (2008b). Pedagogical practice after the information age. Journal of Futures Studies, 12(3), 1-14. 
Matthews, H. (2018, junio 15). 27 Online Dating Statistics \&t What They Mean for the Future of Dating. Dating News. https:// www.datingnews.com/industry-trends/online-dating-statistics-what-they-mean-for-future/

Muratovski, G. (2015). Paradigm Shift: Report on the New Role of Design in Business and Society. She Jl, 1(2), 118-139.

Murnane, K. (2016, marzo 2). Report Shows More People Of All Ages Are Dating Online. Forbes. Recuperado de https:// www.forbes.com/sites/kevinmurnane/2016/03/02/pew-report-who-uses-mobile-dating-apps-and-online-datingsites/\#77a0a62f66e3

Notimex. (2018, octubre 7). Mexican e-commerce industry on the rise. El Universal. Recuperado de: https://www.eluniversal.com. $\mathrm{mx} /$ english/e-commerce-rise

O'Flaherty, K. (2020, junio 16). Microsoft Confirms Crucial New Zoom-Beating Teams Feature. Forbes. Recuperado de https:// www.forbes.com/sites/kateoflahertyuk/2020/06/16/microsoft-confirms-launch-date-for-ultimate-new-zoom-beating-feature/

Pérez, E. (2019, noviembre 20). Millennials: Claves para un futuro más digital. Forbes México. Recuperado de https://www.forbes.com.mx/millennials-claves-para-un-futuro-mas-digital/

Rinne, A. (2019, enero 4). 4 big trends for the sharing economy in 2019. World Economic Forum. Recuperado de https://www. weforum.org/agenda/2019/01/sharing-economy/

Robertson, R. (1992). Globalization: Social Theory and Global Culture. Londres, Reino Unido: Sage

Roudometof, V. (2015). Theorizing glocalization: Three interpretations. European Journal of Social Theory, 19(3), 391-408.

Schmall, T. (2018, octubre 31). Long-distance relationships are more successful than you think. New York Post. https://nypost. com/2018/10/31/long-distance-relationships-are-more-successful-than-you-think/

Schön, D. (1982). The reflective practitioner. New York, NY: Basic Books. Stevanovic, I. (2020, agosto 12). Cozy Coworking Statistics You Need To Know In 2020. Smallbizgenius.
Recuperado de https://www.smallbizgenius.net/by-the-numbers/ coworking-statistics/

Stickdorn, M., y Schneider, J. (2012). This is service design thinking: basics, tools, cases. Hoboken, NJ: Wiley and Sons.

Tabcum, S. (2019, marzo 4). The Sharing Economy Is Still Growing, And Businesses Should Take Note. Forbes. Recuperado de https://www.forbes.com/sites/forbeslacouncil/2019/03/04/ the-sharing-economy-is-still-growing-and-businessesshould-take-note/\#414787604c33

The Design Council. (2007). Eleven lessons: managing design in eleven global brands. A study of the design process. Recuperado de https://www.designcouncil.org.uk/resources/ report/11-lessons-managing-design-global-brands

The Design Council. (2018). The Design Economy 2018. The State of Design in the UK. Recuperado de https://www.designcouncil.org.uk/sites/default/files/asset/document/Design_Economy_2018_exec_summary.pdf

Universia. (2017). Millennials cambian de trabajo cada 28 meses. Recuperado de http://noticias.universia.es/practicas-empleo/ noticia/2017/06/30/1153796/millennials-cambian-trabajo-cada-28-meses.html

Villafranco, G. (2018, febrero 19). Millennials buscan trabajo aunque estén empleados y satisfechos. Forbes. Recuperado de https://www.forbes.com.mx/millennials-buscan-trabajo-aunque-esten-empleados-y-satisfechos/

Vitsoe. (2019). The power of good design. Dieter Rams's ideology, engrained within Vitsœ. Recuperado de https://www.vitsoe. com/eu/about/good-design

\section{Contribución autoral}

a) Concepción y diseño del trabajo; b) Adquisición de datos; c) Análisis e interpretación de datos; d) Redacción del manuscrito; e) revisión crítica del manuscrito.

R. L. L. ha contribuido en $a, b, c, d$, e. 